\title{
WORKSHOP PEMBUATAN MEDIA PEMBELAJARAN INOVATIF BERBASIS IPTEK BAGI GURU SD TERPENCIL DI KECAMATAN SABBANGPARU
}

\author{
${ }^{1 *}$ Yetti Anita, ${ }^{2}$ Rudi Karma ${ }^{3}$ Sri Wahyuni dan ${ }^{4}$ Nur Rahmi \\ 1,2,3,4 STKIP Puangrimaggalatung Sengkang \\ Sulawesi Selatan, Indonesia. \\ *Email:yuni_core@yahoo.com
}

\begin{abstract}
ABSTRAK
Tujuan pelaksanaan program PKM ini adalah: (a) Membentuk kelompok kerja guru(KKG), (b) meningkatkan pengetahuan dan keterampilan para guru tentang pembuatan media pembelajaran dengan pendekatan IPTEK terapan, (c) melatih pembuatan media pembelajaran dengan pendekatan IPTEK terapan, (d) melatih dan mendampingi cara penggunaan media pembelajaran di kelas. Metodepelaksanaan kegiatan menggadopsi pola pelaksanaan penelitian tindakan meliputi empat tahap,yaitu: perencanaan program, pelaksanaan program, observasi dan evaluasi, dan refleksi. Hasil pelaksanaan program adalah (a) terbentuk 7 kelompok kerja guru dengan masingmasinganggota sebanyak 4 sampai 9 orang yang dibentuk berdasarkan lokasi daerah; (b) adanya peningkatan pengetahuan dan keterampilan para guru tentang pembuatan media pembelajaran dengan pendekatan IPTEK terapan, dari kategori "cukup" menjadi "baik"; (c) dihasilkan media (alat peraga) untuk siswa SD,(d) kemampuan guru dalam menggunakan media pembelajaran dalamdi kelas berkualitas "baik".
\end{abstract}

Kata kunci: Pembuatan Media,SD Terpencil

\begin{abstract}
The objectives of this PKM program are: (a) To form teacher working group (KKG), (b) to improve teachers' knowledge and skill about making instructional media with applied science and technology approach, (c) to train the making of instructional media with applied science and technology approach ) to train and assist the use of instructional media in the classroom. The method of adopting the action research implementation includes four stages: program planning, program implementation, observation and evaluation, and reflection. The results of program implementation are (a) 7 teacher working groups with 4 to 9 members formed based on the location of the area; (b) the increased knowledge and skills of teachers on the making of instructional media with applied science and technology approach, from the "enough" to the "good" category; (c) generated media (props) for elementary students, (d) teachers' ability to use instructional media in "good" quality classes.
\end{abstract}

Key words : Making Media, Remote SD

\section{PENDAHULUAN}

Lokasi Kecamatan Sabbang paru Kabupaten Wajo, sekitar 20 km dari kota Sengkang. Sekolah Dasar yang ada di Kecamatan Sabbang paru sebanyak 34 sekolah.Lokasi sekolahsekolah tersebut, sebagian besar terletak di daerah pedesaan sehingga kegiatan P2M di bidang pendidikan yang dilakukan oleh Perguruan Tinggi sangat jarang sampai ke wilayah-wilayah tersebut. Lokasilokasi sekolah yang sebagian besar terletak pada daerah yang agak terpencil mengakibatkanpara guru jarang terlibat dalam kegiatankegiatan ilmiah yang dilakukan olehdinas pendidikan dan Perguruan Tinggi. Sebagai dampaknya pengetahuan dan pemahaman para guru di wilayah ini masihkurang terkait dengan desain pembelajaran 
ataupun inovasi-inovasi terbaru kegiatan

pembelajaranlainnya.Berdasarkan

hasil wawancara dengan beberapa guru dan kepala sekolah di SD 81 Mallusesalo,SDN 241 Ugi dan SDN 337 Salotengah yang dilakukan pada bulan Mei 2017, diperoleh informasibahwa, pembelajaran yang dilaksanakan selama ini sangat jarang menggunakanmedia, khususnya yang berupa alat peraga ataupun mediamedia inovatif lainnya. Siswa belajarlebih banyak melalui penjelasan secara langsung oleh guru yang didominasidengan pemberian ceramah.Hal ini terjadi sebagai akibat dari sarana dan prasarana khususnyaterkait dengan media pembelajaran yang tersedia sangat kurang, khususnya tentang mediamanipulatif belum adadan pemahaman serta keterampilan guru untuk merancang mediapembelajaran juga sangat kurang. Sebagai akibatnya siswa belajar dengan cara-cara yang kurang bermakna.Siswa cenderung menghafal konsep atau prosedurmatematis tertentu dan belajar lebih banyak secara mekanistik.Hal ini berdampakpada rendahnya prestasi belajar yang dicapai siswa dan pembelajaran berlangsung dengan membosankan.

\section{SOLUSI DAN TARGET LUARAN}

\section{Solusi}

Sehubungan dengan permasalahan yang dihadapi oleh mitra tersebut, maka berdasarkan analisis tim pengusul serta hasil wawancara dengan kedua mitra PKM ini akan diberikan solusi dengan rencana kegiatan sebagai berikut : (1) Pembentukan/Pembinaan kelompok kerja guru (KKG) yang diharapkandapat mengatasi permasalahan pembelajaran dan mampu menjadi wahanadalam memfasilitasi pengembangan profesionalisme para guru SD di pedesaan.(2) Melakukan workshop bagi guru-guru untuk menambah pengetahuan para guru tentang penerapan IPTEKS untuk merancang mediapembelajaran yang inovatif dan m emiliki kemampuan untukmengimplementasikannya dalam kegiatan pembelajaran. (3) Menambah wawasan para guru terkait dengan pengelolaan KKG secara efektif danoptimal.

\section{Target Luaran}

Target yang ingin dicapai melalui kegiatan PKM ini adalah sebagai berikut.

(1) Teridentifikasinya konsep-konsep bahasa Indonesia SD yang esensial yang bisa diajarkan denganlebih mudah kalau menggunakan media pembelajaran inovatif. Sebagai kriterianya adalah minimal 50\% materi pembelajaran SD dapat dibuatkan media/alat peragayang inovatif. (2) Adanya kelompokkelompok kerja Guru bahasa Indonesia (KKG) dengan kemampuan IPTEKterapan dalam memproduksi media pembelajaran. Sebagai kriterianya adalahminimal $60 \%$ dari guru mitra memiliki pengetahuan yang 'cukup' dalam memproduksimedia pembelajaran yang inovatif. (3) Adanya produk media pembelajaran yang inovatif beserta cara pengepakkandan dilengkapi dengan petunjuk penggunaannya, dengan target produksi mediapembelajaran minimal 10 alat peraga inovatif.(4) Adanya peluang untuk mengembangkan jiwa kewirahusahaan, dengan memproduksiberbagai media 
pembelajaran yang inovatif yang memiliki nilai jual.

\section{METODE PELAKSANAAN Metode Penerapan Ipteks}

Untuk

melaksanakan

pengabdian masyarakat dengan tema workshop pembuatan mediapembelajaran inovatif berbasis iptek bagi guru SD terpencil di kecamatan sabbangparu dilakukan dengan melakukan beberapa tahapan prosedur kerja, yakni Tindakan dalam kegiatan ini berupa implementasi Program. Kegiatan-kegiatan yang dilakukan dalam implementasi program adalah (a) pembentukan kelompok-kelompok kerjaguru (KKG), (b) meningkatkan pengetahuan dan keterampilan para guru tentang pembuatanmedia pembelajaran dengan pendekatan IPTEK terapan,

mendemonstrasikanteknologi

pembuatan media pembelajaran dengan pendekatan IPTEKS terapan,(d) pembinaan dan pelatihan teknologi pembuatan media pembelajaran bahasa, dan (e)pelatihan cara penggunaan media pembelajaran dalam pembelajaran di kelas. Terakhir adalah tahap evaluasi dan monitoring yang akan dilaksanakan pada bulan ke tujuh dan delapan.

Observasi dilakukan terhadap proses pembuatan media pembelajaran olehpara guru mitra. Instrumen yang digunakan berupa catatan lapangan. Beberapa hal yangdiobservasi adalah kendalakendala, kekurangan-kekurangan, dan kelemahan-kelemahanyang muncul dalam proses pembuatan di lapangan maupun dalam proses penggunaan dikelas.

\section{Rancangan Evaluasi}

Evaluasi dilakukan terhadap kuantitas dan kualitas produk yang dihasilkan.Produkyang dihasilkan dalam kegiatan pelatihan ini adalah media pembelajaran inovatif.Kuantitasnya dilihat dari banyaknya alat peraga/media yang dihasilkan oleh para guru, sedangkan kualitasnya terlihat dari meningkatnya hasil belajar siswa darisebelumnya.

\section{Partisipasi Mitra Dalam Pelaksanaan Program}

Mitra dari kegiatan ini adalah guru-guru di SD 81 Mallusesalo,SDN 241 Ugi dan SDN 337 Salotengah, Kecamatan Sabbangparu, Kabupaten Wajo. Seluruh mitra untuk selanjutnya, dibimbing secara penuh untuk menerapkan dalam pelatihan yang dilakukan. Dari kegiatan ini diharapkan akan terjadi pertukaran pengetahuan sehingga akan berdampak pada peningkatan pengetahuan para mitra. Peran serta aktif mitra sangat berpengaruh terhadap kelangsungan kegiatan yang dilakukan.

\section{HASIL DAN PEMBAHASAN}

Hasil yang dicapai melalui kegiatan PKM ini dituangkan dalam bentuk hasil kegiatan pada setiap tahap pelaksanaan sebagai berikut:

\section{Hasil Kegiatan}

Kegiatan yang dilakukan disini berupa implementasi Program PKM. Kegiatan-kegiatan yang dilakukan dalam implementasi program adalah sebagai berikut. (a) Meningkatkan pengetahuan dan keterampilan para guru melalui pelatihan tentang model-model pembelajaran. (b) Meningkatkan pengetahuan dan keterampilan para 
guru tentang pembuatan media pembelajaran inovatif dengan pendekatan IPTEK terapan. Kegiatan ini dilakukan melalui pemberian pelatihan tentang pembuatan media pembelajaran dan penggunaannya. Pemberian teori dilakukan dalam 3 hari kegiatan pelaksanaan dilakukan pada tanggal 14-16 April 2018 bertempat di SD 337 Salotengah, dilanjutkan dengan kegiatan praktek di masing-masing sekolah mitra dibawah bimbingan tim pelaksana

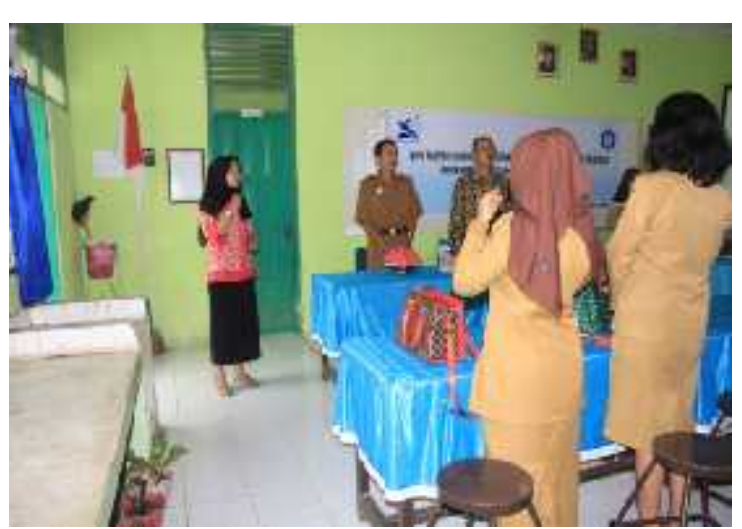

Gambar 1. Pembukaan Workshop

PKM. (c) mendemonstrasikan teknologi pembuatan media pembelajaran, dilakukan dengan cara mengaplikasikan langsung pada kegitan belajara mengajar di kelas. (d) Pembinaan dan pelatihan pembuatan media pembelajaran dan (e) pelatihan cara penggunaan media pembelajaran dalam pembelajaran di kelas. Kegiatan ini dilakukan sampai akhir bulan Oktober, luaran kegiatan berupa beberapa media pembelajaran inovatif dari beberapa mata pelajaran di SD.

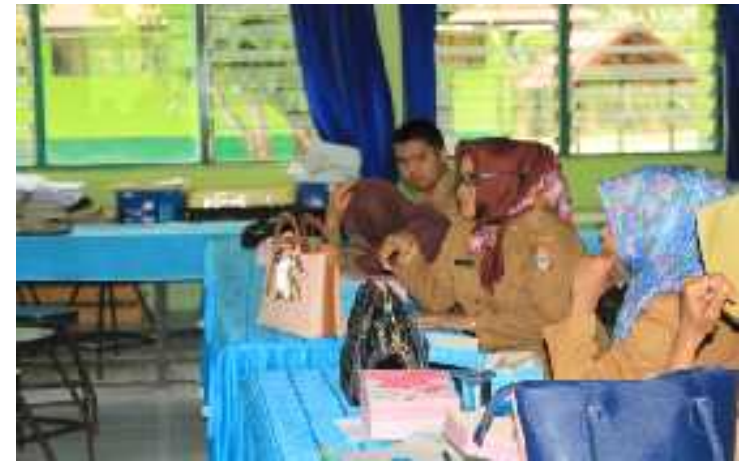

Gambar 2. Pelaksanaan pelatihan

Produk yang dihasilkan dalam kegiatan ini adalah media pembelajaran inovatif. Kuantitasnya dilihat dari banyaknya alat peraga/media yang dihasilkan oleh para guru, sedangkan kualitasnya terlihat dari meningkatnya hasil belajar siswa dari sebelumnya. Instrumen evaluasi adalah lembar penilaian berupa alat penilaian kemampuan mengajar guru (APKG) termasuk rencana pelaksanaan pembelajaran (RPP) yang dibuat oleh guru. Penilaian terhadap kualitas RPP dan kemampuan mengajar guru dilakukan menggunakan rubrik penskoran dengan skala Likert dengan rentangan skor 1 sampai 5 . Beberapa hal yang diobservasi adalah kendala-kendala, kekurangankekurangan, dan kelemahankelemahan yang muncul dalam proses pembelajaran berbantuan media inovatif di kelas. Kendala yang dihadapi sebagian besar guru dalam pelaksanaan pembelajaran berbantuan media inovatif adalah penguasaan terhadap materi masih kurang. Media yang digunakan masih secara klasikal, penggunaannya belum bisa dimanipulasi langsung oleh siswa. Namun melalui penggunaan media yang dipandu oleh guru, siswa telah berhasil belajar dengan cara yang lebih bermakna karena mereka dipandu untuk bisa menemukan 
konsep dari simulasi media tersebut. Evaluasi dilakukan terhadap kemampuan guru dalam mengimplementasikan media pembelajaran dalam kegiatan pembelajaran di kelas. Instrumen yang digunakan adalah alat penilaian kemampuan guru. Hasil evaluasi adalah rata-rata kemampuan mengajar guru menggunakan media pembelajaran yang telah dikembangkan berkualitas "baik" dan RPP yang disusun guru, berkualitas "baik". Rata-rata hasil belajar matematika siswa mengalami peningkatan.

\section{PEMBAHASAN}

Kegiatan PKM yang dilaksanakan pada guru-guru SD di Kecamatan Sabbangparu telah berlangsung dengan baik. Hal ini terlihat dari animo guru untuk mengikuti kegiatan pelatihan sangat tinggi, terbukti dengan kehadiran para guru untuk mengikuti kegiatan mencapai $90 \%$. Hal ini mengindikasikan bahwa para guru menyambut positif kegiatan yang telah dilakukan. Sesuai dengan harapan para sekolah, mereka sangat mengharapkan adanya kegitankegiatan yang sifatnya memberi penyegaran bagi para guru di daerah ini, baik terkait dengan pendalaman materi bidang studi ataupun terkait dengan metode mengajar, mengingat hampir $60 \%$ dari para guru sudah berumur di atas 40 tahun. Kepala sekolah, kepala UPTD, dan pengawas, menyambut antusias terkait pelaksanaan kegiatan PKM ini. Pengawas yang hadir, berharap agar dilakukan kegiatan secara berkesinambungan dan disarankan untuk mengembangkan media yang disusun untuk materi materi yang lain.
Pengawas dan kepala UPTD juga berharap agar ada pembinaan dari perguruan tinggi di daerah ini untuk meteri olimpiade. Dalam kegiatan pelatihan, para guru sangat antusias dalam mempraktekkan alatalat peraga (media) yang telah disusun dalam kegiatan peer teaching. Banyak masukan yang diberikan, baik oleh para guru ataupun oleh tim pelaksana PKM terkait dengan pelaksanaan pembelajaran berbantuan media inovatif. Masukan yang diberikan oleh tim pelaksana PKM lebih banyak tentang pendalaman materi bidang studi terkait dengan media yang dikembangkan. Guru-guru didampingi untuk melaksanakan pembelajaran menggunakan media inovatif pada kelas dan sekolah di masing-masing. Melalui kegiatan pendampingan, pelaksanaan pembelajaran berbantuan media inovatif dapat berlangsung dengan baik. Rata-rata hasil belajar siswa mengalami peningkatan dari sebelum pelaksanaan pembelajaran berbantuan media dengan setelah pelaksanaan pembelajaran berbantuan media. Kendala-kendala yang dihadapi dalam pelaksanaan PKM ini adalah masalah waktu pelaksanaan dan keterlambatan pencairan dana, sehingga waktu pelaksanaan kegiatan menjadi mundur, tidak bisa berlangsung sesuai dengan rencana. Namun, semua kendala dan masalah yang muncul telah dicarikan solusinya, Dengan demikian kegiatan PKM ini telah berlangsung dengan baik.

\section{KESIMPULAN DAN IMPLIKASI}

Berdasarkan pemaparan seluruh kegiatan Program Kemitraan Masyarakat (PKM) yang telah 
dilakukan maka dapat disimpulkan bahwa sejumlah target luaran telah dapat dicapai diantaranya yaitu: (a). Terbentuk kelompok kerja guru (KKG) dengan masing-masing anggota sebanyak 4 sampai 9 orang, berdasarkan distribusi lokasi sekolah.(b). Adanya peningkatan pengetahuan dan keterampilan para guru tentang pembuatan media pembelajaran inovatif dari kategori "cukup" menjadi "baik" (c). Dihasilkan sebanyak media (alat peraga) mata pelajaran matematika, Bahasa Indonesia dan IPA untuk siswa SD. (d). Rata-rata kemampuan mengajar guru menggunakan media pembelajaran yang telah dikembangkan, berkualitas "baik". (e). Rata-rata hasil belajar siswa mengalami peningkatan sebelum pelaksanaan pembelajaran berbantuan media dan setelah pelaksanaan pembelajaran berbantuan media.

\section{UCAPAN TERIMA KASIH}

Terimakasih penulis ucapkan kepada seluruh pihak yang telah membantu pelaksanaan kegiatan pengabdian kepada masyarakat ini, diantaranya:

1. Kementrian Riset dan Teknologi yang telah membiayai pelaksanaan kegiatan pengabdian ini sehingga dapat berjalan dengan baik serta memberikan manfaat kepada masyarakat.

2. STKIP Puangrimaggalatung Sengkang dan Lembaga Pengabdian dan Penelitian STKIP Puangrimaggalatung Sengkang yang telah turut serta memberikan kesempatan kepada tim pengabdi untuk melaksanakan pengabdian ini.

3. Rekan dosen dan pegawai serta mahasiswa STKIP Puangrimaggalatung Sengkang yang telah banyak membantu hingga terlaksananya kegiatan pengabdian ini.

4. Serta seluruh pihak yang tidak dapat penulis sebutkan yang telah membantu pelaksanaan kegiatan.

\section{DAFTAR PUSTAKA}

Dick, W., Carey, L., \& Carey, J. O. 2011.The Systematic Design Of Instruction. USA: AddisonWesley Educational Publisher Inc

Gall, M. D., Gall, J. P., \& Borg, W. R. 2003.Educational research: An introduction. Seventh Edition. Boston: Pearson Education, Inc.

Heinich, R., Molenda, M., Rusell, J. D., \& Smaldino, S.E. 2012.Instructinal media and technology for larning, 7th edition.New Jersey: Prentice Hall, Inc.

Januszewski, A., Molenda, M. 2008. Educational Technology. New York: Lawrence Erlbaum Associates.

Martha, E. R. D., Rosalind, H. \& Ted, W. P. 2003. Theory and Research in Social Education.Vol. 4. Washington DC: NCSS. 